\title{
MODEL TESTS ON THE CONFIGURATION OF SLIP SURFACE
}

\author{
Eitaro Yamaguchi*, Yoshiaki MiYahara*, Rikushi Nakamura* and \\ Masateru TAKAYAMA*
}

\section{INTRODUCTION}

To investigate the stress distribution, the deformation by consolidation, the change of shearing strength or pore water pressure developed in the soil, the condition of failure surface due to loading by embakment and the method to control the rate of construction reasonably which is an important items with respect to the stability of reclamation embankment, various tests were projected and are now carried on.

The fundamental ideas understanding the above subjects through these tests are to infer the distribution of effective pressure and the deformation of soil from measuring the excess pore water pressure in the field, and to connect above results with ones of stress, strain and time relation obtained laboratory testing.

Two papers for "The Similarity Law for Model Tests in Soil Mechanics." and " The Strength Properties of Clay Remolded by Consolidation Pressure." have been published. The whole aspects of the test results can not be presented at present stage, however, owing to incompletion of measurements on pore water pressure. High sensitive piezometers of the foil-gauge type were used for the measurements, the measured values were influenced by temperature variations that correction is needed to interprete the test data properly. Consequently, the presumption of failure is only limited qualitatively except the configuration of slip surface which is the main subject descrided in this paper.

Strictly speaking, although the influence of side friction working between wall and soil should be considered as this test was carried out in two-demensional state, it was disregarded here because the friction may be negligible small for the soil of high water content.

\section{THE OUTLINES OF TESTS}

\section{1) Construction of Foundation Soil}

In these tests, a bin was used whose size is $3 \mathrm{~m}$ in width, $0.3 \mathrm{~m}$ in depth and $1.0 \mathrm{~m}$ in height, of which front side is covered with reinforced glass plate, and the soil tested was the clay or soft mud taken from the reclamation field at Ariake district under the control by the Ministry of Agriculture and Forestry.

After removing shells and the like included in, the soil was shaked with water, placed into the bin uniformly and consolidated under the pressure of $0.2 \mathrm{t} / \mathrm{m}^{2}$ keeping the initial water content to be constant. The model foundation soil was thus obtained

* Agricultural Civil Engineering Experiment Institute, The Ministry of Agriculture and Forestry. 
at the completion of consolidation which was confirmed by doing the settlement observation every day. It took two to three months for the consolidation.

The physical properties of soil, the conditions when it was compacted in the bin or the change in soil caused by consolidation may be refered to the previous report ${ }^{2}$. The surface layer of $7 \mathrm{~cm}$ thick was removed as it was over strengthend by consolidation.

The soil conditions were prescribed as following.

$\begin{array}{ll}\text { Initial water content } & 200 \text { per cents. } \\ \text { Consolidation pressure } & 0.2 \mathrm{t} / \mathrm{m}^{2} \\ \text { Initial thickness of clay layer } & 65 \mathrm{~cm} . \\ \text { Final thickness of clay layer } & 56 \mathrm{~cm} . \\ \text { Total settlement } & 9 \mathrm{~cm} . \\ \text { Time for consolidation } & 60-90 \text { days. }\end{array}$

\section{(2) The Method of Loading}

Deformation of the embankment follows easily the subsoil settlement, embankment was formed by piling up the iron bars horizontally whose diameter is $1 \mathrm{~cm}$, such as the outer shape of piled bars is similar to the cross section of embankment. Eighty two bars was placed closely at the bottom and its scale was about one to fifty of actual embankment in Ariake area.

Tests were classified as follows :

A) the case when load was applied at constant rate directly on the uniform soil without any foundation,

B) the case when load was applied at various rates on the soil through tapered sand bed,

C) the case when first load was less than permissible bearing capacity and then load was increased at constant rate,

D) the case when load was applied on the soil through sand beds of various thickness. (3) Measurement of Deformation and Determination of Slip Surface

The soil deforms and the soil particles move as load was increased. Various methods were tried to record these phenomena by photograph.

A) The mixture of vaseline and powdered aluminium was put on the inside face of the glass plate along square net at $5 \mathrm{~cm}$ intervals, and by this method the deformation could be traced fairly well but the net became irregualr in the early stage of consolidation especially when the water content was excessively high such 200 per cents.

B) Deformation of the soil was visible by the observation of the density of spots due to brown mold grew on the glass plate during the construction of base soil. When the displacement increased and the soil surface was heaved, then the brown mold scratched by the movement of soils. So that the density of mold spots were changed at the slip surface.

However these spots are so obscure that we put marks with chalk on both these spots and cracks so as to give a clear image on film. 


\section{EXPLANATION OF PHOTOGRAPHIES}

Eight photos of A-1 to A-8 presented here show the process of growth of slip surface which started from the small cracks or local failure and developed to the slip surface or general failure finally. The rate of loading and the number of times of loading until failure was brought about are shown in the margine of the photos.

In case of $\mathrm{A}$, the fairly uniform soil was obtained after removing the surface layer of $7 \mathrm{~cm}$ thick which had been over strengthened as shown in the margine of A-1.
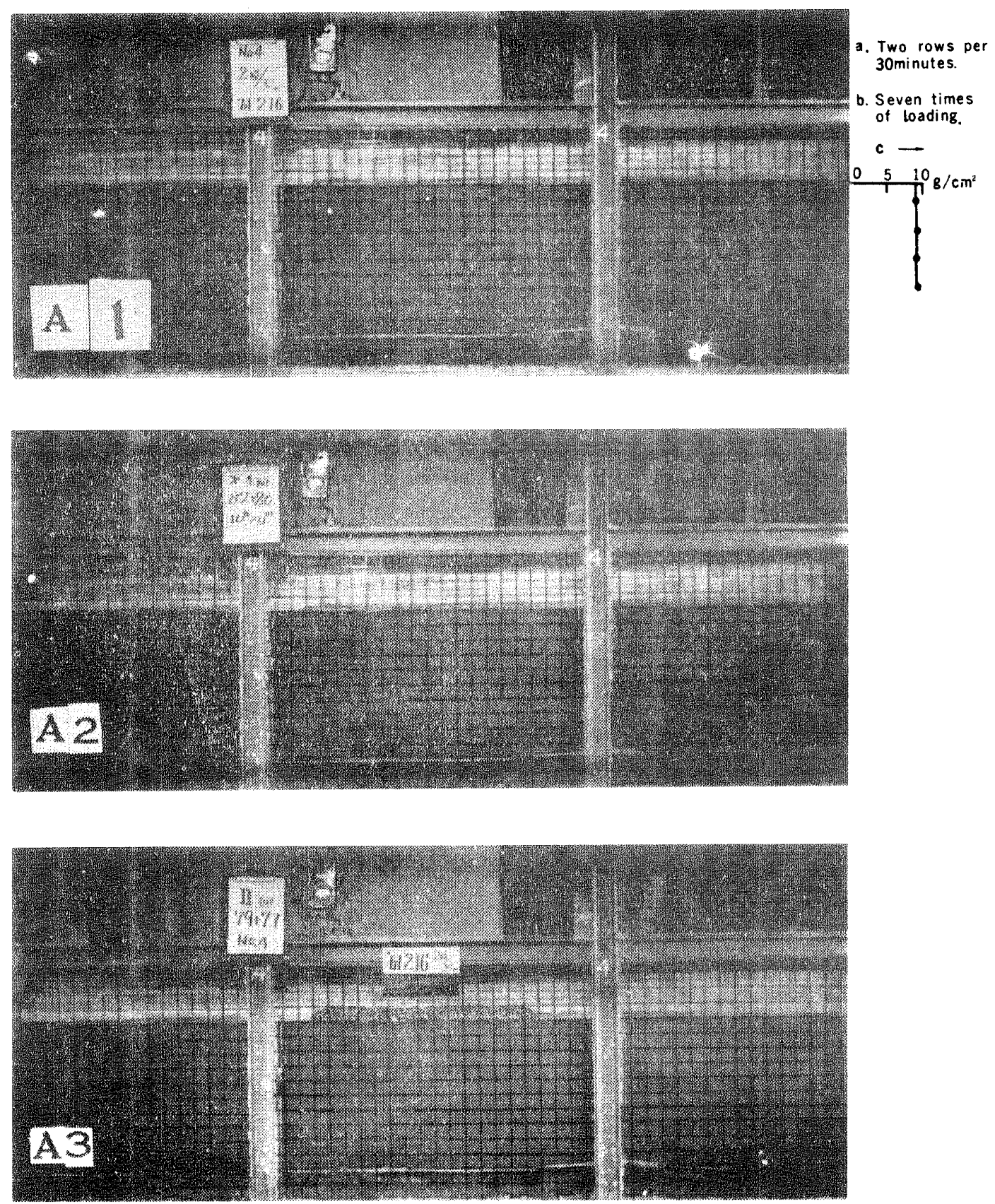

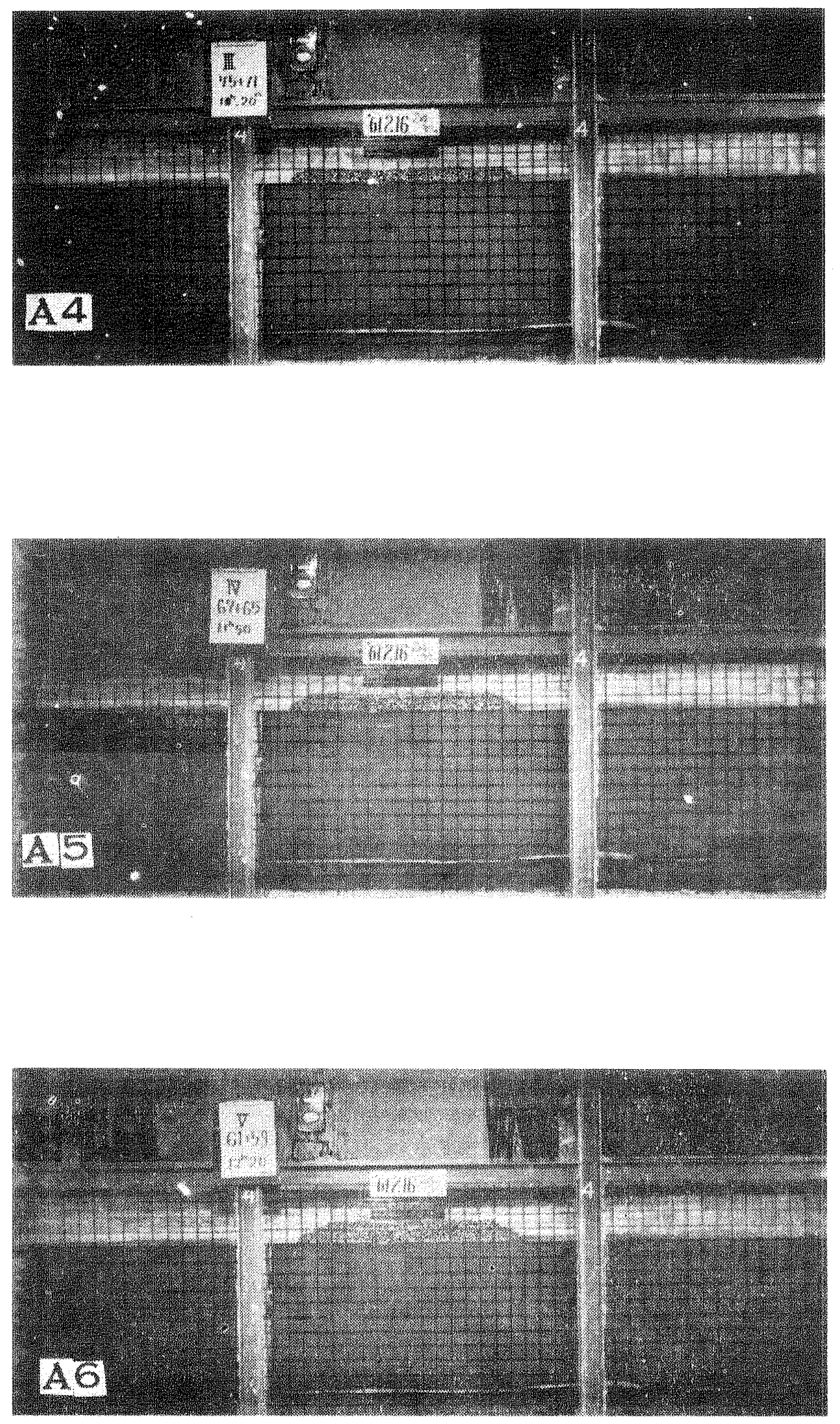

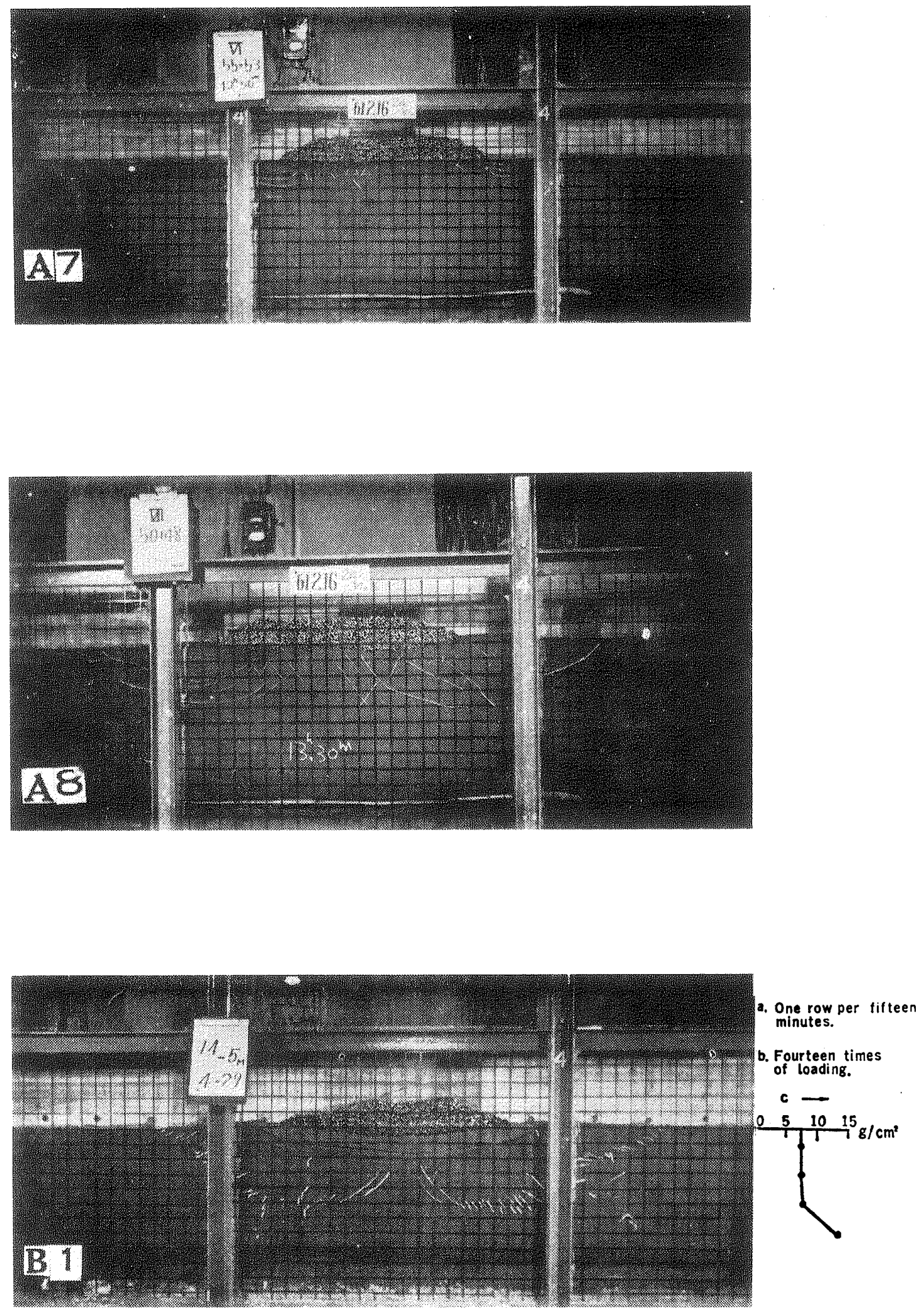

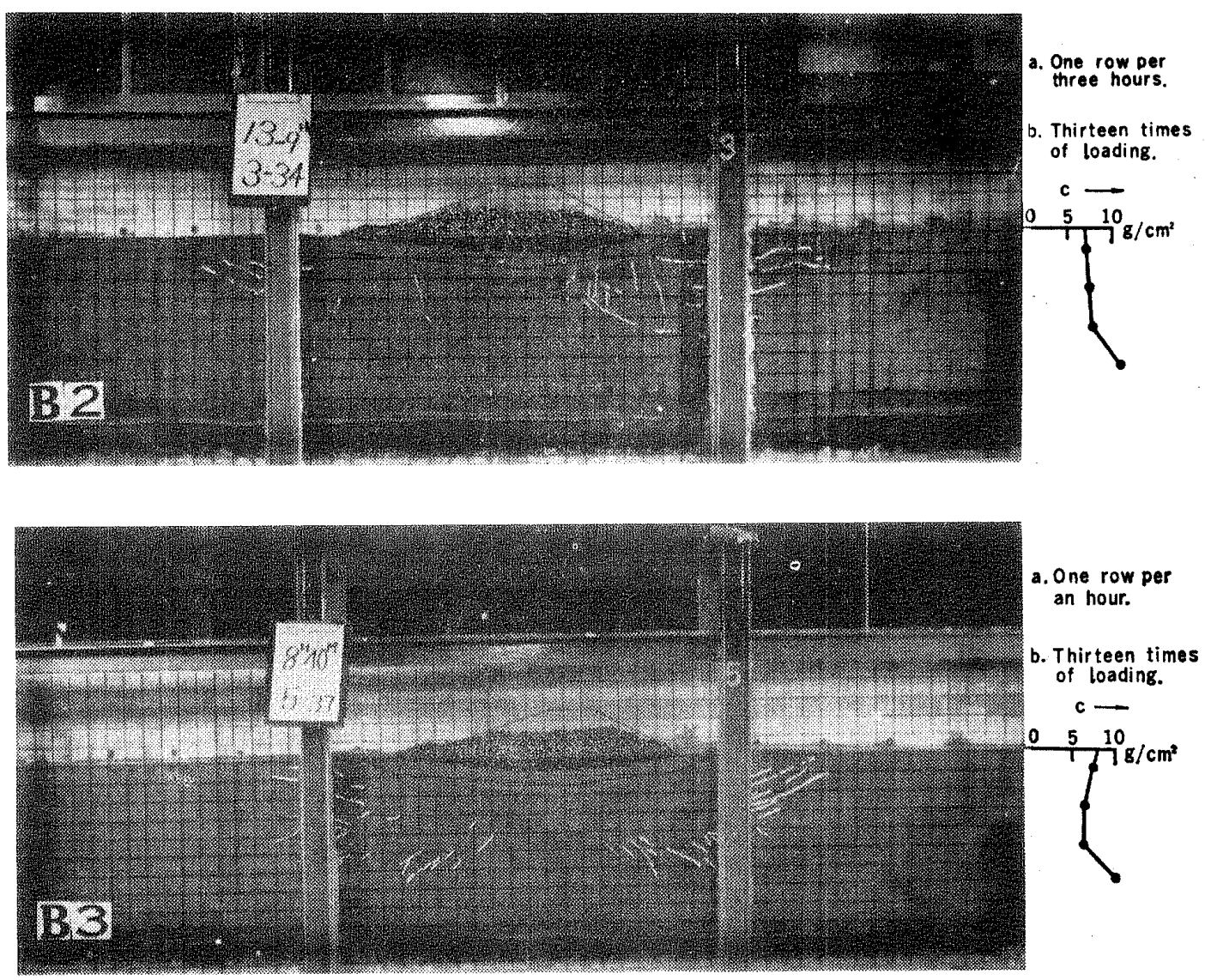

Loading was so adjusted that the failure would occur after the end of sixth or seventh loading. In this case loading bars were piled up in double rows at every 30 minutes. In A-2, A-3 and A-4 the rows are counted four, six and eitgh respectively. In A-7 the first and second row begin to sink in the soil and appear cracks simultaneously namely the plastic flow arises near the toe and many cracks appear forming wedge shape beneath the embankment.

In $\mathrm{A}-8$, it is shown that these wedges or cracks together develop in the region located above the slip zone and remarkable sinking follows.

It may be allowed to suppose the load in the stage of A-6 where little settlement occurs yet, being the permissible bearing value. The cracks beneath the load observed in A-7 vanish and these are replaced by a slip zone caused by the confluence of each crack in A-8.

In $B$ group the soil has uniform strength down to $30 \mathrm{~cm}$ deep, in these tests the load was applied at various rates. All slip surfaces issue from the center of embankment as similarly shown in $\mathrm{A}-8$, this is the most normal type of sliding which can be prevented by the control of loading. It should be remarked that the bottom of failure surface touches on the surface where the soil strength increases sharply.

In $\mathrm{C}$ group the load is applied at constant rate under various initial load on the soil surface without any foundation. 

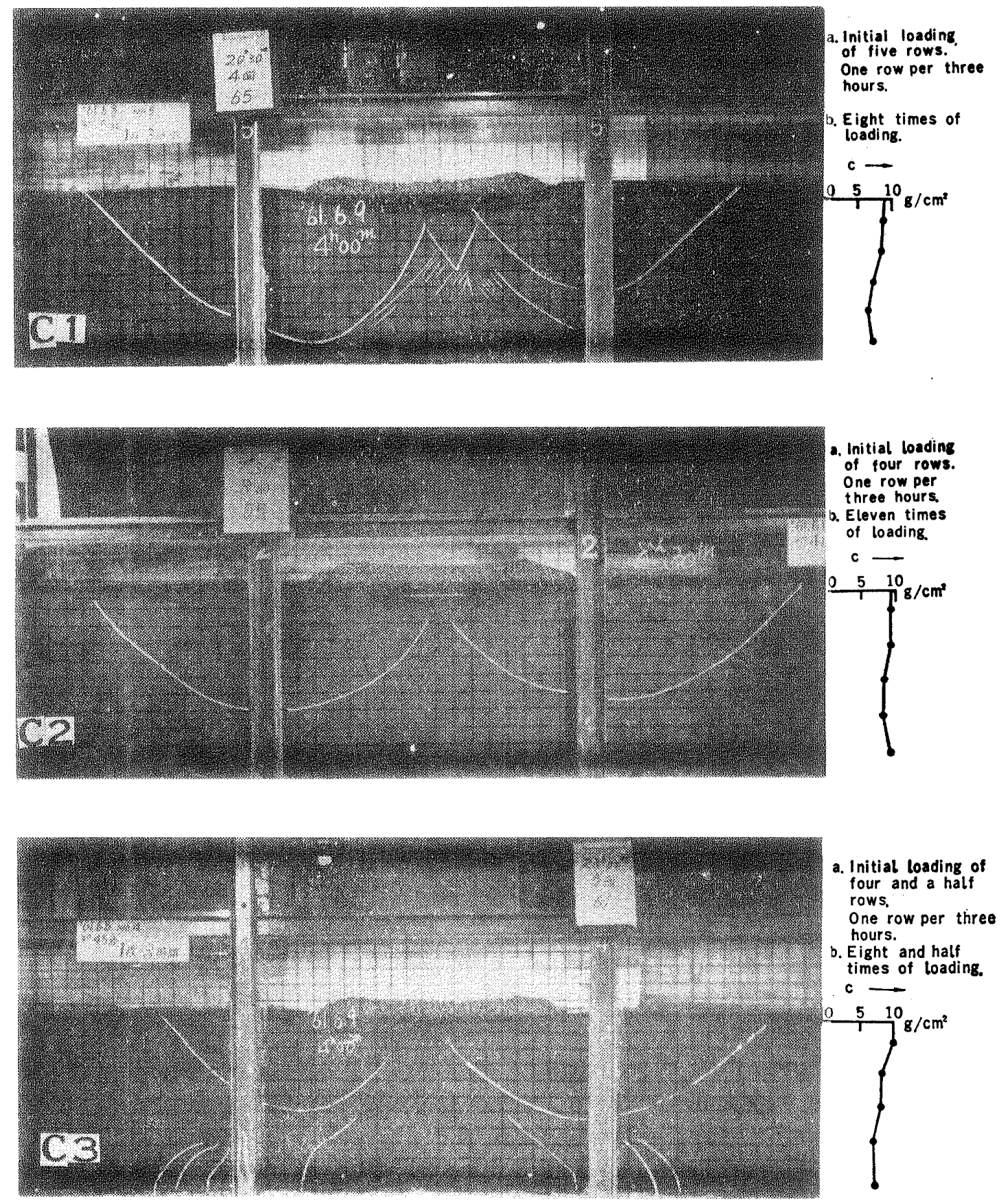

In every cases of the group, the lower part of soil remains to be weak due to the insufficient consolidation. In C-1, the wedge of Kurudumoff is observed beneath nearly at the center of the embankment and two automatic settlement recorders are installed at the center of the embankment and at the point one fourth of the width from edge of the embankment respectively. This is the special type of sliding, and slip surfaces resemble to a quasi circle whose lower portion is sharpened a little. In these photos, (C-1 to C-3) the widths of slip surface are almost same though some deviations of the 
depth are observed. The unsymmetry if existed depends on the nonuniformity of the soil.

Heaving is not so large because the failure zone spreads widely.

In the tests of D group, the thickness of sand bed was changed.

Although there is some difference of shear strength vertically between D-1 and D-2, the bearing power is larger in D-2 case whose sand bed is thicker than that of D-1. On the other hand, the slip surfaces are similar in shape and counter-balances of sand layer are forced up in both cases, which indicate the decrease of shear strength at the end of slip zone.

To set up thicker sand bed or deep foundation is understood to be effective to increase the bearing power and the economical thickness will be limited to about $5 \mathrm{~m}$ for Ariake clay from view point of replaced soil mass.
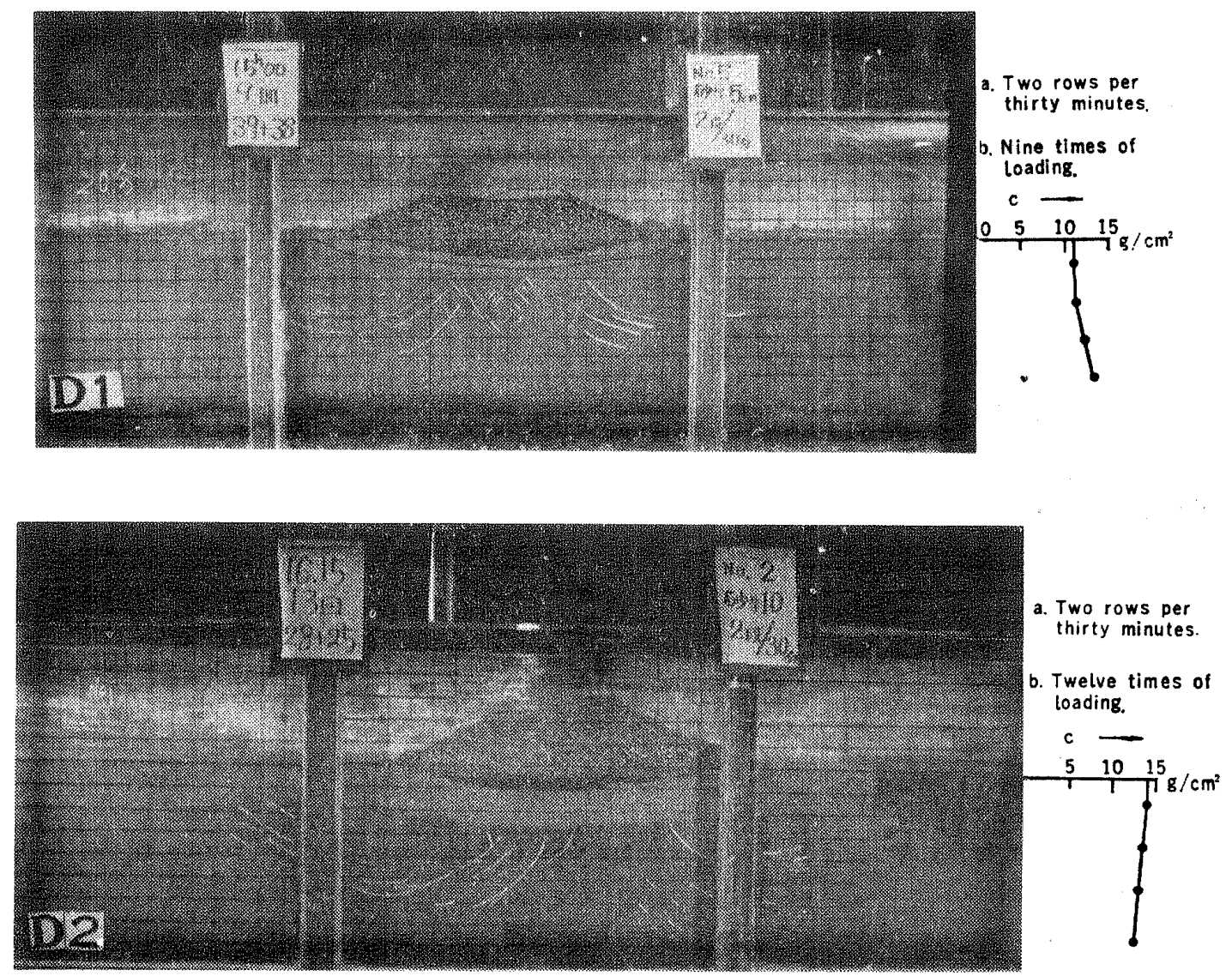

Two examples in which the strength of soil increases sharply in its shallow portion and the local sliding occurs are presented in E group.

This sliding is distinguished by abrupt settlement and excess heaving and is perhaps resulted by the local sinking following the extreme weakening in small portion of soil where slide comes up. E-1 is the photo where soil is uniform without sand bed and E-2 sand bed is provided. In the one case without sand bed the failure occurs rapidly 
and in the other with sand bed it occurs progressively. This phenomenon was ascertained generally.
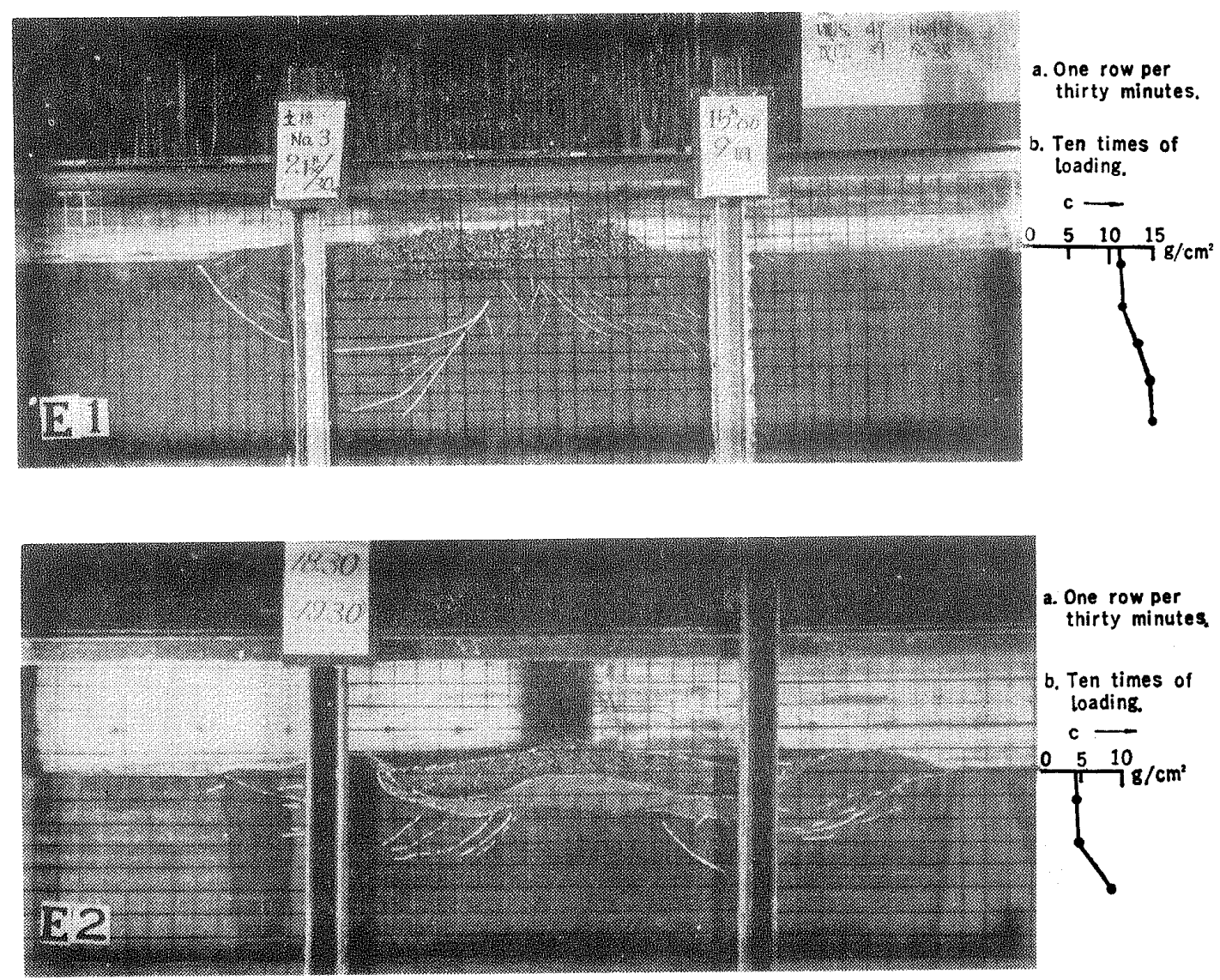

\section{CONSIDERATIONS ON SLIPZONE}

(1) Does slip surface exist?

Slip surface herein stated is limited to the two-dimensional case. As the loading goes on, soil is divided into two regions; in one part movement is observed and soil particles are at rest in the remainder.

Sliding phenomenon is a general term named on such deformations as rotational, shearing or rigid movements. When soil slides, active or passive zone and the transient zone between them were recognized experimentally.

By the way in sliding the existence of slip zone is conservative. So-called slip zone is nothing but the configuration of small cracks or it is identical with shearing layer.

Slip zone in its proper meaning appears when each crack confluents macroscopically and in one place this zone is so thin as to become linearly and in other crack may vanish.

Generally speaking, in active region many numbers of crack grow at first and these develop locally into large slip zone finally, in transient region one observes the growth of grouped cracks in nearly horizontal direction which come together in two or three 
zones, among these the largest one being the governer in the failure, and in passive region the existence of slip zone can not be seen so clearly that any direction is possible of slip zone direction, but if remotely stated one may consider the boundary between cracks and resting zone to be slip zone.

As the conclusion it can be said that though the clear line like a slip surfce is not observed, there still exists a strip which should be recognized slip zone. Until the slip zone is developed, creep occurs initially and it is followed by the large slip deformation.

(2) In waht way does slip zone develop?

Load is applied step by step in the tests. A few cracks or local failure is seen to issue when load reaches about seventy per cents of the ultimate bearing power, and then this develops gradually to general failure as load increases. Even if the load is kept in some value over seventy per cents of ultimate power, slip zone may be still developed with the progression of settlement caused by creep deformation. To simplify the condition authors consider the case only where the rate of loading is constant. It should be noted the sliding grows steadily without regard the position whence it starts. In all cases, a few small cracks produced at the beneath of nearly middle point of embankment increases in its size and number with the increase of load and settlement, and these cracks extend downward along the direction with an angle of $(\pi / 4+\delta)$ to the horizontal line though some of them vanish as the result of crushing due to large deformation.

One can observe the growth of small cracks locally both in transient and passive zone as the centre portion of embankment settles. The directions are almost horizontally in transient zone and make an angle of $(\pi / 4-\delta)$ to the horizontal plane in passive zone.

Cracks in passive zone do not vanish unlike active zone, and extend in deeper portion without change the initial configuration. Authors consider the zone connected the lowest parts of these cracks being slip zone. However the detailed shapes of slip zone both in transient and passive zone is assumed to be fairly influenced by the soil conditions or the shape and size of embankment.

Saying concludingly, in final stage cracks remain only in slip zone or active condition and these serve to form a slip surface, in transient taste cracks concentrate horizontally at the near portion of slip zone and developed. to a slip zone as deformation increases. On the other hand slip zone is meant by the trace connecting the lower end of each crack zone in passive ares.

The features of these three types of slip zone can be distinguished clearly by observation.

(3) To what configuration does slip zone resemble?

The figures of slip zone are definitely like a circle both in active and transient zone and convex upwards in passive zone, though these zones can not be distinguished so clearly, and the transient zone seems to be not so large as imagined.

In routine work of calculation concerning the stability analysis of reclamation embankment three methods have been adopted as that 
(1) Critical Circle method,

(2) Reissner-Caquot method,

(3) Logarithmic Spiral method.

As stated above, the actual failure of slip zone resembles to that of (1) in active zone excepting that figure may be assumed by that of (2) when the soil is not uniform, in transient zone this can be represented by that of (2) or (3) and in passive zone though the proposed figure in (2) gives the approximate curve but difference should be recognized in its trend of curvature. Moreover the slip configurations given in (2) and (3) can not be applied in the soil with finite depth because these pass through rather deeper portion, and difficulty will be found when setting the slip line definitely. Such being the case, critical circle method is used in the computation. Though this method based on trial treatment being troublesome it is applicable for the case with various kinds of boundary condition, for example the critical circle may be considered to pass through or touch the surface bounded by two layers with different shear strength, and when soil becomes stronger gradually downward, the circle with minimum safety factor may be located as it touches the surface leveled at two third or three fifth of the total depth.

The influence of the gradient of the increase in strength in above trend in more detail is the subject of future investigation.

(4) How influenced is slip zone by soil condition?

As explained before, slip zone is known as a circle whose bottom part is laid on the surface where the shear strength changes abruptly, or strength lowers excessively and if this surface exist in shallower portion sliding occurs locally in the vicinity of the toe of embankment.

When the embankment is supported by sand bed, above statement will be still conservative if the bottom of sand bed is supposed to be the new surface.

(5) How coincide the assumed slip surface with an actual one?

It is recognized that the curve consisting of a circle and a straight line which is the tangent of the above circle with the inclination angle of thirty or fourty degrees resembles closely to an actual slip surface, on the other side logarithmic spiral passes through rather deep portion as stated before.

(6) Conclusion

The followings are obtained with respect to the configuration of slip zone.

1) A circle is a good curve to represent the slip surface approximately when the soil is uniform or its irregularity is simple.

2) The strength of soil has influence only on the ultimate bearing power and little influence on the configuration of slip surface.

3) When sand bed is set up the bearing power increases with the magnitude of thickness, and the depth of slip surface is increased by the bed thickness without remarkable change in its shape. Consequently, for comparatively uniform soil the effect of sand bed is larger than that of counterweighting for the increase of stability. 


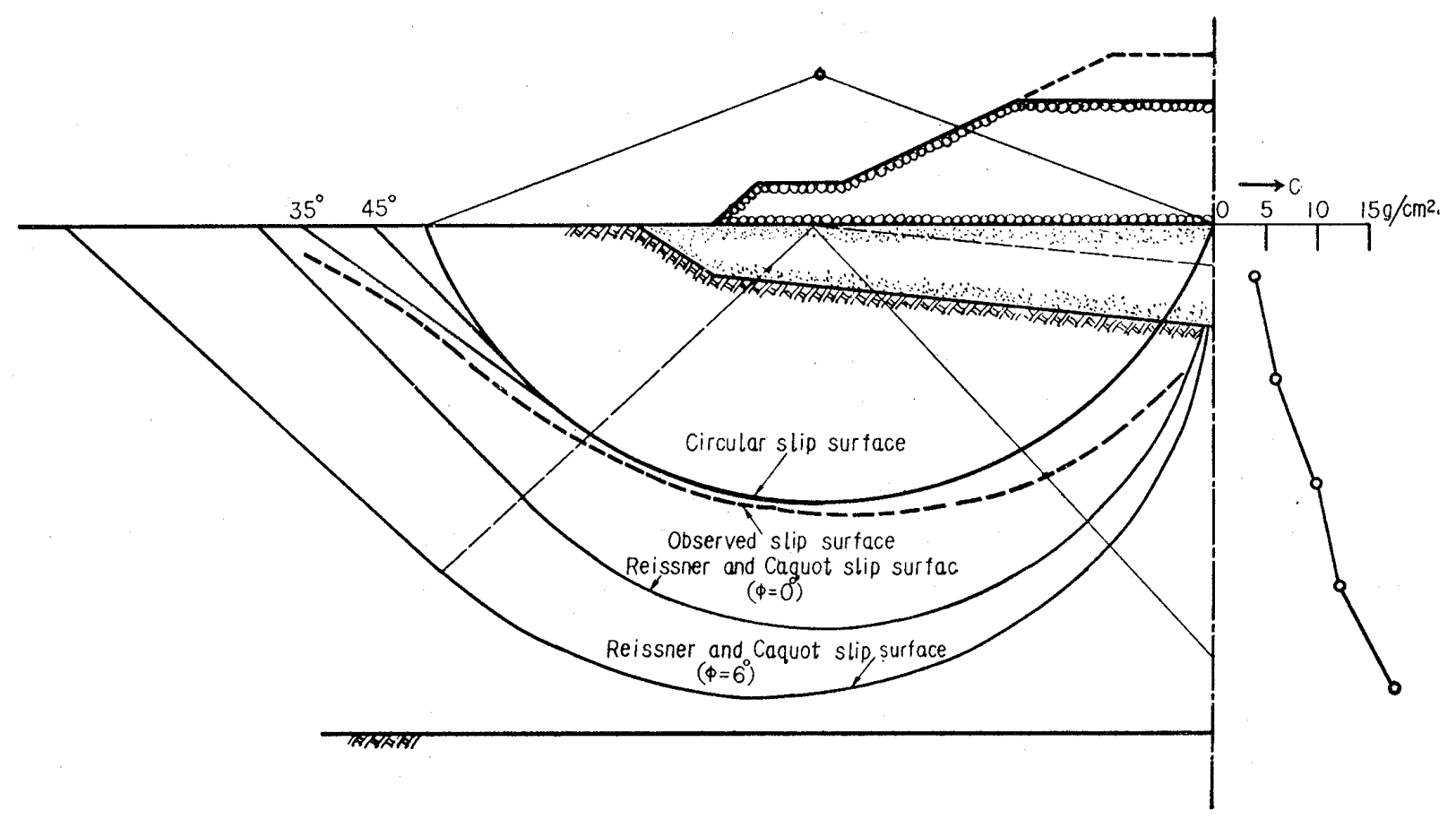

\section{REFERENCES}

1) YAMAGUCHI, Eitaro, Y. MIYAHARA and M. NAKAMURA: The Similarity Law of Model Tests in Soil Mechanics, presented at the Lecture Meeting held by the Kyushu Branch of the Japan Society of Agronomists, 1958.

2) YAMAGUCHI, Eitaro, Y. MIYAHARA, M. YAMAKAWA, and M. TAKAYAMA: On the Strength Properties of Clay Remolded by Consolidation Pressure, Tsuchi to Kiso, Vol. 8, No. 4, 1960. 